\title{
Editorial
}

\section{Pesquisa científica e saúde}

I Kenneth Rochel de Camargo Jr. |

No Comentário desta edição, Teodoro e Caetano abordam o affair fosfoetanolamina, chamando a atenção para os riscos representados por essa exceção para o sistema de proteção ética aos direitos de sujeitos de pesquisas com medicamentos, bem como para a segurança geral da população. Com efeito, é preocupante ver como esse triste episódio foi apropriado por defensores do PL 200/2015 do Senado como apoio à proposta que, como apontou em nota a Abrasco (ABRASCO, 2015), compromete severamente o processo de controle ético da pesquisa farmacêutica ao enfraquecer o papel da CONEP. Isso é ainda mais preocupante considerando-se que os resultados dos testes in vitro realizados por demanda do Ministério da Ciência, Tecnologia e Inovação mostraram, na melhor das hipóteses, um efeito pífio de uma substância presente nas cápsulas produzidas (não a fosfoetanolamina, diga-se) que, a propósito, não continham apenas aquele composto. $\mathrm{O}$ mesmo estava presente em quantidades variáveis que não correspondiam ao conteúdo suposto, mostrando também problemas no próprio processo de síntese (BRASIL/MCTI, 2016).

É possível pensar, entretanto, num escopo mais amplo a partir desse episódio, infelizmente ainda não encerrado - num país com recursos cada vez mais escassos para a pesquisa, está se investindo desproporcionalmente num produto que já fracassou espetacularmente nos testes iniciais. Há uma questão de fundo nesse processo, que é o lugar da ciência nos processos de intervenção terapêutica.

Ao longo das décadas que nos separam do pós-Segunda Guerra Mundial, foram desenvolvidos paulatinamente dispositivos técnicos e burocráticos para assegurar, o tanto quanto possível, a eficácia e segurança dos medicamentos em uso pela população. Em alguns casos, impulsionados por tragédias como a da talidomida. 
O desenvolvimento mais recente dos estudos sobre ciência (science studies) trouxe um olhar crítico sobre tais processos, mostrando suas vicissitudes e limitações de forma palpável, deixando bem claro o caráter de empreendimento humano da ciência. Paralelamente, diversos estudos expuseram ocasiōes em que a indústria farmacêutica recorreu à manipulação de estudos científicos para alavancar suas vendas (GOLDACRE, 2013), às vezes com resultados catastróficos, como no caso do rofecoxib.

Essas contribuiçôes justificam um saudável ceticismo sobre a produção de conhecimentos terapêuticos a partir da ciência; com frequência, porém, esse ceticismo desvala para um niilismo cínico, e que se acopla paradoxalmente a uma adesão acrítica a outras modalidades terapêuticas, essas tidas como isentas de qualquer conflito de interesses, riscos ou manipulações.

Esse estado de coisas reflete o problema que Latour apontou há tempos, de uma crítica que deixa de proteger a sociedade de uma suposta ciência que faz afirmações hiperbólicas em relação às suas possibilidades, para se prestar à desestabilização da ciência perfeitamente razoável e confiável (LATOUR, 2004). Latour clama nesse texto: "Por que queima minha língua dizer que o aquecimento global é um fato caso você goste ou não? Por que não posso simplesmente dizer que a discussão foi definitivamente encerrada?" Ou ainda, vale lembrar Collins e Pinch, quando afirmam que na medicina, a ciência, sobretudo quando sujeita a essa crítica sistemática, ainda é a melhor aposta (COLLINS; PINCH, 2008).

A necessária crítica à ciência - parte integral da própria ciência - não pode ser confundida com uma recusa tola e irresponsável ao conhecimento penosamente construído por gerações de pesquisadores. Especialmente em se tratando de sistemas (ainda) públicos de saúde, a demonstração por meios pactuados da eficiência e segurança de intervenções traz ainda a questão do financiamento de tais sistemas; a incorporação de tecnologia duvidosa é também um desperdício de recursos públicos.

Canguilhem dizia da clínica que não se tratava de uma ciência, com toda razão. Mas dizia também que ela é uma prática que se utiliza de meios cuja eficácia é cada vez mais garantida cientificamente (CANGUILHEM, 1966), e disso não podemos abrir mão. 


\section{Referências}

ABRASCO. Projeto de lei do Senado ${ }^{\circ}$ 200, de 2015, retira da sociedade brasileira o controle das pesquisas envolvendo seres humanos - ABRASCO. Disponível em: <https:// www.abrasco.org.br/site/2015/04/projeto-de-lei-do-senado-no-200-de-2015-retira-dasociedade-brasileira-o-controle-das-pesquisas-envolvendo-seres-humanos/>. Acesso em: 08 ago. 2016.

BRASIL. Ministério da Ciência, Tecnologia e Inovação. Relatório do Seminário sobre estudos preliminares da Fosfoetanolamina Sintética (FOS). Disponível em: <http://www.mcti.gov. br/documents/10179/1274125/Relat\%C3\%B3rio+do+Semin\%C3\%A1rio+sobre+estudo s+preliminares + da+Fosfoetanolamina+Sint \%C3\%A9tica+\%28FOS\%29/2ca3e868-e3be491f-9301-ff7bb3ccb99d>. Acesso em: 08 ago. 2016.

CANGUILHEM, G. Le normal et le pathologique, augmenté de Nouvelles réflexions concernant le normal et le pathologique. Paris: Quadrige, 1966.

COLLINS, H.; PINCH, T. Dr. Golem: how to think about medicine. Chicago: University of Chicago Press, 2008.

GOLDACRE, B. Bad Pharma: How drug companies mislead doctors and harm patients. Toronto: Random House LLC, 2013.

LATOUR, B. Why has critique run out of steam? From matters of fact to matters of concern. Critical Inquiry, v. 30, p. 225-248, 2004. 